\title{
Comparison of Composite Methods of Satellite Chlorophyll-a Concentration Data in the East Sea
}

\author{
Kyung-Ae Park ${ }^{\star \dagger}$, Ji-Eun Park**, Min-Sun Lee ${ }^{\star \star}$ and Chang-Keun Kang ${ }^{\star \star *}$ \\ *Department of Earth Science Education / Research Institute of Oceanography, Seoul National University \\ **Department of Science Education, Seoul National University \\ *** Ocean Science and Technology Institute, Pohang University of Science and Technology
}

\begin{abstract}
To produce a level-3 monthly composite image from daily level-2 Sea-viewing Wide Field-ofview Sensor (SeaWiFS) chlorophyll-a concentration data set in the East Sea, we applied four average methods such as the simple average method, the geometric mean method, the maximum likelihood average method, and the weighted averaging method. Prior to performing each averaging method, we classified all pixels into normal pixels and abnormal speckles with anomalously high chlorophyll-a concentrations to eliminate speckles from the following procedure for composite methods. As a result, all composite maps did not contain the erratic effect of speckles. The geometric mean method tended to underestimate chlorophyll-a concentration values all the time as compared with other methods. The weighted averaging method was quite similar to the simple average method, however, it had a tendency to be overestimated at high-value range of chlorophyll-a concentration. Maximum likelihood method was almost similar to the simple average method by demonstrating small variance and high correlation $(r=0.9962)$ of the differences between the two. However, it still had the disadvantage that it was very sensitive in the presence of speckles within a bin. The geometric mean was most significantly deviated from the remaining methods regardless of the magnitude of chlorophyll-a concentration values. Its bias error tended to be large when the standard deviation within a bin increased with less uniformity. It was more biased when data uniformity became small. All the methods exhibited large errors as chlorophyll- $a$ concentration values dominantly scatter in terms of time and space. This study emphasizes the importance of the speckle removal process and proper selection of average methods to reduce composite errors for diverse scientific applications of satellite-derived chlorophyll-a concentration data.
\end{abstract}

Key Words : Chlorophyll-a, Composite, East Sea, Ocean Color

\section{Introduction}

Satellite-observed chlorophyll- $a$ concentration data have been widely used to investigate spatial and temporal variabilities to understand changes in oceanic ecology over past decades. To understand the impact of climate change and global warming on the oceanic biosphere environment and feedback

Received November 3, 2012; Revised December 8, 2012; Accepted December 10, 2012.

${ }^{\dagger}$ Corresponding Author: Kyung-Ae Park (kapark@snu.ac.kr)

This is an Open-Access article distributed under the terms of the Creative Commons Attribution Non-Commercial License (http://creativecommons.org/licenses/by-nc/3.0) which permits unrestricted non-commercial use, distribution, and reproduction in any medium, provided the original work is properly cited. 
procedure between the two, the accuracy of satelliteobserved chlorophyll- $a$ concentration, as a measure of phytoplankton levels in the sea water, has been more important (e.g. Jeong and Yoo, 2002; Yoon et al., 2005; Chae and Park, 2009; Kim et al., 2010; Park et al., 2012). O’Reilly et al. (1998) highlighted that ocean color data conveyed essential information about the global carbon cycle and other biogeochemical processes.

Sea-viewing Wide Field-of-view Sensor (SeaWiFS) has become one of the most important ocean color sensors in the observation of global ocean color distribution. It operated from 1998 to 2007 and provided the ocean color community with valuable information to conduct diverse research. It followed the Coastal Zone Color Scanner (CZCS), which operated from 1978 to 1986 (e.g. Hooker et al., 1992; McClain et al., 1995). Although the Moderate Resolution Imaging Spectroradiometer (MODIS) ocean color sensor has become one of the most important ocean color sensors that is currently in operation, SeaWiFS data has continued to play an important role in establishing long-term time-series ocean color data.

The Distributed Active Archive Center (DAAC) at NASA's Goddard Space Flight Center (GSFC) has produced several types of chlorophyll- $a$ concentration data such as level-2 daily Global Area Coverage (GAC) or Local Area Coverage (LAC) data with spatial resolutions of about 4.5 kilometers and one kilometer respectively, as well as level-3 data. Level3 data with a resolution of $9 \times 9 \mathrm{~km}^{2}$, a statistical product derived from level-2 data, are composited for each period of a given day, 8 days, a month, or a year (Hooker et al., 1992; Campbell et al., 1995). To generate level-3 data, diverse composite methods such as the simple average, the geometic mean, the maximum likelihood estimation and the weighted average have to date been applied .

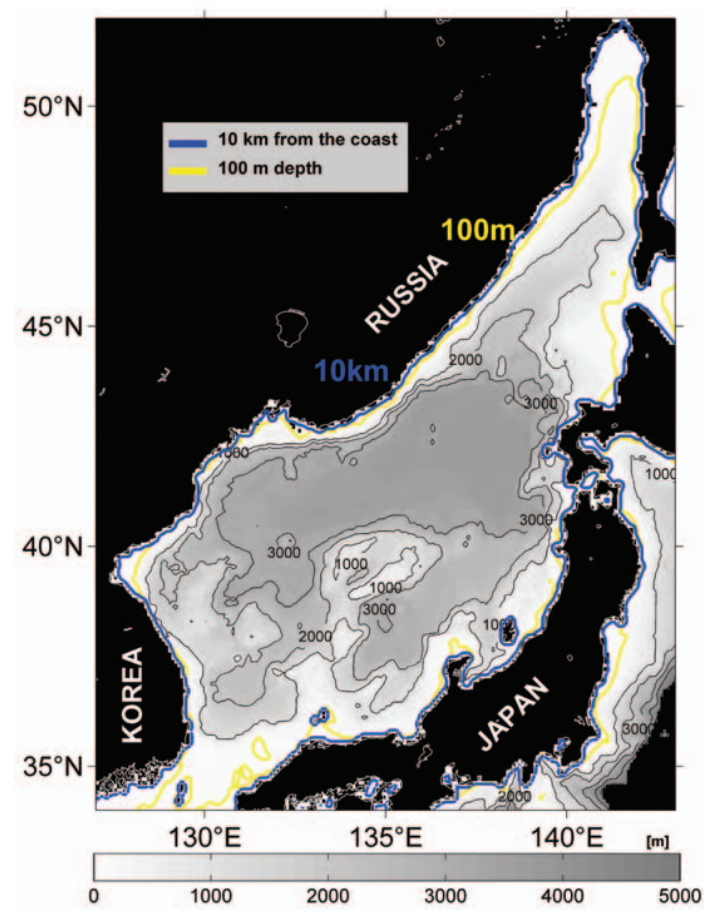

Fig. 1. Bathymetry of the study area.

Chae and Park (2009) and Park et al. (2012) have demonstrated the characteristics of chlorophyll- $a$ concentration distribution and identified errors including speckles with anomalously high chlorophyll- $a$ concentration values in the East Sea (Fig. 1). They further emphasized the importance of the speckle removal procedure prior to performing research which integrates diverse scientific applications. In general, the East Sea is classified into Case-1 water according to Morel and Prieur (1977), which is contrast with Case-2 water of the Yellow Sea. Case-1 water is referred to waters whose optical properties are dominated by phytoplankton and their associated degradation products (Gordon and Morel, 1983; Moon et al., 2010). It is found nearly all open sea situations including both oligotrophic waters and highly productive upwelling regions with dominant phytoplankton blooms. By contrast, Case-2 water applies to coastal waters with lots of particulate material, land-derived yellow substance, river inputs, 
and land drainage such as the Yellow Sea and most of the western coast of Korea (Ahn and Moon, 1998; Ahn, 2000; Suh et al., 2002; Ryu et al., 2007).

The objectives of this study are to (1) eliminate erratic speckles, (2) apply different average methods in the generation of level-3 gridded monthly chlorophyll- $a$ concentration in the East Sea as Case-1 water, (3) compare results from the different methods, and (4) address and discuss the selection of a proper averaging method by considering regional characteristics of chlorophyll- $a$ concentration data.

\section{Data}

\section{1) SeaWiFS}

We used an updated version of daily four kilometer level-2 (GAC) data (http://oceancolor.gsfc. nasa.gov/WIKI/OCReproc.html/). Since the objectives of this study are limited to comparing differences between average methodologies, we did not extend the study period to the whole SeaWiFS period from 1998 to 2007. To test and compare each composite method, we selected all daily images only in April 2003 over the entire region of the East Sea as shown in Fig. $1\left(34-52^{\circ} \mathrm{N}, 127-143^{\circ} \mathrm{E}\right)$. The number of daily images used in the composite process amounted to 45 in total. In addition to level-2 data, we have also used a monthly-averaged map of chlorophyll- $a$ concentration data in April 2003, with a spatial resolution of $9 \times 9 \mathrm{~km}^{2}$ based on Hooker et al. (1992) and Campbell et al. (1995).

Chlorophyll- $a$ concentration values were estimated by using remote sensing reflectances at visiblewavelength bands (443, 490, 510, and $555 \mathrm{~nm}$ ) derived from the following equation (1) based on Ocean Color 4 (OC4) version 4 algorithm (Feldman, 2010) :

$$
\begin{aligned}
\mathrm{CHL} & =10^{0.3272-2.9940 R+2.7218 R^{2}-1.2259 R^{3}-0.5683 R^{4}} \\
\mathrm{R} & =\log _{10}\left(\frac{\mathrm{R}_{\mathrm{rs}} 443>\mathrm{R}_{\mathrm{rS}} 490>\mathrm{R}_{\mathrm{rS}} 510}{\mathrm{R}_{\mathrm{rS}} 555}\right)
\end{aligned}
$$

\section{2) MODIS}

To compare the composite maps of chlorophyll- $a$ concentration from the SeaWiFS database with other pre-existing monthly maps, we used the Moderate Resolution Imaging Spectroradiometer (MODIS) map in April 2003. The scheme for the production of level-3 binned product is similar to procedures for SeaWiFS. The mapped MODIS products were provided at three different spatial resolutions: four kilometers, nine kilometers and one degree, and at daily, weekly (eight-day), monthly and yearly temporal increments. Of various versions, we selected monthly products with both four kilometer and nine kilometer resolutions to be compared with monthly SeaWiFS composited images.

\section{Method}

\section{1) Speckle removal process}

Previous research illustrated that a lot of speckles were evident in SeaWiFS chlorophyll- $a$ concentration images in the East Sea due to characteristic atmospheric and oceanic conditions, particularly in winter. The number of speckles was relatively small on average, except for winter. However, they were still clearly apparent and may generate serious problems on each composite map. Therefore, the speckles with significant chlorophyll- $a$ concentration errors should be eliminated prior to applying the composite procedure (Hu et al., 2001).

We followed the methodology developed by Park 
Table 1. Summary of averaging methods of chlorophyll-a concentration from satellite data

\begin{tabular}{c|c|c|c|c}
\hline \hline Method & Simple Average & Geometric Mean & $\begin{array}{c}\text { Maximum Likelihood } \\
\text { Estimation }\end{array}$ & Weighted average \\
\hline Description & $\begin{array}{c}\text { Linearly- averaged } \\
\text { arithmetic mean }\end{array}$ & $\begin{array}{c}\text { Logarithmically- } \\
\text { averaged } \\
\text { geometric mean }\end{array}$ & $\begin{array}{c}\text { Maximum likelihood } \\
\text { estimate of the mean for data } \\
\text { with a lognormal distribution }\end{array}$ & $\begin{array}{c}\text { Weighted average by } \\
\text { giving weight depending } \\
\text { on the number of data points }\end{array}$ \\
\hline Equation & $\bar{X}_{\text {avg }}=\frac{1}{n} \sum_{i=1}^{n} X_{i}$ & $\bar{X}_{\text {geom }}=\exp \left[\frac{1}{n} \sum_{i=1}^{n} \ln X_{i}\right]$ & $\bar{X}_{m l e}=\exp \left[m+\frac{s^{2}}{2}\right]$ & $\bar{X}_{\text {weighted }}=\frac{1}{W} \sum_{i=1}^{N} \frac{1}{\sqrt{n_{i}}} \sum_{j=1}^{n_{i}} X_{i j}$ \\
\hline Satellite & $\begin{array}{c}\text { SeaWiFS, MODIS } \\
\text { NASA }\end{array}$ & $\begin{array}{c}\text { OCTS, GLI } \\
\text { NASDA }\end{array}$ & $s^{2}=\frac{1}{n} \sum_{i=1}^{n}\left[\ln X_{i}-m\right]^{2}$ & $\mathrm{~W}_{i=1}^{n} \sqrt{n_{i}}$ \\
\hline \hline
\end{tabular}

et al. (2012), which was optimized for the East Sea. First, we removed pixels at shallow coastal regions by excluding data at areas within 10 kilometers of the coast. Then, the pixels at shallow regions with a water depth of less than 100 meters were discarded in the speckle removal process, as denoted respectively in the blue and yellow lines in Fig. 1.

We then considered the spatial uniformity of chlorophyll- $a$ concentrations within a $5 \times 5$ window $\left(\sim 0.2^{\circ} \times 0.2^{\circ}\right)$ to consider the seasonal difference of absolute chlorophyll- $a$ concentration values by applying normalization procedures. We then considered some criteria for chlorophyll- $a$ concentration fronts. Detailed procedures for the speckle removal process were presented in Park et al. (2012).

\section{1) Simple average method}

Various ocean-color missions employ different binning algorithms in several ways. For instance, they use different spatial and temporal bin sizes, calculating binned data statistics in different ways and use different schemes for weighting data in each bin (IOCCG, 2004). Four methods describing the averaging of data are included in Table 1.

One of the easiest methods to estimate the composite field is the simple averaging of a set of values, which is known as an arithmetic mean or a simple linear average. It is the standard average, $\bar{X}_{a v g}$, often simply called the 'mean' as follows:

$$
\bar{X}_{a v g}=\frac{1}{n} \sum_{i=1}^{n} X_{i}
$$

where $X_{i}$ is an individual chlorophyll- $a$ concentration value and $n$ is the total number of time series data at a given pixel within a given period on average.

\section{3) Geometric mean}

Previous literature has reported that chlorophyll- $a$ concentration values undergoing oceanic biological processes tended to be log-normally distributed from both satellite data and oceanic in-situ measurements (e.g. Aitchison and Brown, 1957; Campbell et al., 1995; Crow and Shimizu, 1988). For this reason most research has displayed chlorophyll- $a$ concentration images in a logarithmic scale rather than in a usual normal scale, unlike other oceanic variables.

We can take an average of the logarithmic-scale to estimate the geometric average $\left(\bar{X}_{\text {geom }}\right)$ as follows:

$$
\bar{X}_{\text {geom }}=\exp \left[\frac{1}{n} \sum_{i=1}^{n} \ln X_{i}\right]
$$

where $\ln$ represents the natural log. Firstly, it converts normal chlorophyll- $a$ concentration values to logarithmic-scale values. We then took the simple linear average such as (2), and returned it to an original scale by applying the exponential function. In 
short, the practice of transforming data first, computing the mean of log-transformed data and then estimating the mean of $X$ gives the geometric mean.

\section{4) Maximum likelihood estimate}

When data variances are large and sample sizes are small, the maximum likelihood estimation (MLE) of the mean of a log-normal distribution can perform better than the previous two methods (Baker and Gibson, 1987). The MLE is obtained from the following equation:

$$
\begin{gathered}
\bar{X}_{m l e}=\exp \left[m+\frac{s^{2}}{2}\right] \\
m=\frac{1}{n} \sum_{i=1}^{n} \ln X_{i} \\
s^{2}=\frac{1}{n} \sum_{i=1}^{n}\left[\ln X_{i}-m\right]^{2}
\end{gathered}
$$

where $m$ is the sample mean of $\ln (X)$ and $s^{2}$ is the sample variance.

\section{5) Weighted average method}

When the size of a bin on average is bigger than that of a pixel, each set of spatial pixels within a bin can have on $n_{i}$ observations from the same orbital pass. For each set of data with $\mathrm{N}$ observations with respect to a time $t_{i}(i=1, \cdots, \mathrm{N})$, a weighted mean $\bar{X}_{\text {weighted }}$ and variance $s^{2}$ of the data over observation $x_{i j}$ can be estimated as follows :

$$
\bar{X}_{\text {weighted }}=\frac{1}{W} \sum_{i=1}^{N} \frac{1}{\sqrt{n_{i}}} \sum_{j=1}^{n_{i}} X_{i j}
$$

where the sum of the weights $W$ is

$$
\mathrm{W}=\sum_{i=1}^{N} \sum_{i=1}^{n_{i}} \frac{1}{\sqrt{n_{i}}}=\sum_{i=1}^{N} \sqrt{n_{i}}
$$

and $j$ refers to the $j$ th observation at time $t_{i}(i=1, \cdots$, $\mathrm{N}$, and $\left.j=1, \cdots, n_{i}\right)$. Recall that observation value $x_{i j}$ $=\ln \left(X_{i j}\right)$ (Campbell et al., 1995). Table 1 summarized the four average methods as mentioned previously.

\section{6) Chlorophyll-a concentration front}

In order to remove speckle pixels in the frontal region, we used chlorophyll- $a$ concentration frontal values. The frontal magnitude $F$ was obtained from the magnitude of two-dimensional gradient vector of chlorophyll- $a$ concentration at each grid point:

$$
F=\mid \nabla \text { chlorophyll- } a \text { concentration } \mid
$$

\section{Results}

\section{1) Characteristics of daily observations}

Fig. 2 displays the time-series of level-2 SeaWiFS chlorophyll- $a$ concentration images in April 2003. The number of the daily images amounted to 45 . In some cases, there were two images at 2UT and 4UT for consecutive satellite passes as shown on 1 April, 2003. Although a representatively clear month of spring was selected, none of the images could entirely cover the entire region. In general, the poor cloud coverage was induced by various atmospheric features such as a variety of cloud types, sea fog, haze, dust, aerosol, and many other atmospheric obstacles. Due to the accurate process of atmospheric correction and the cloud removal scheme of NASA/GSFC, many pixels seemed to be lost, resulting in the utilization of only the clearest pixels in the estimation of a chlorophyll- $a$ concentration average map (Hu et al., 2000).

Since missing pixels with respect to time and space may have an influence on the final composited value, one should collect as many images as possible to produce a composite map with more spatial coverage during a given period. Fig. 3(a) shows the number of pixels with satisfactory chlorophyll- $a$ concentration data from SeaWiFS for April, 2003. We applied all the quality flags to daily level-2 images provided by NASA/GFSC to maintain the accuracy of chlorophyll- $a$ concentration values for a better composite map. The maximum number of good data within a $9 \times 9 \mathrm{~km}^{2}$ grid for the month amounted to 15 


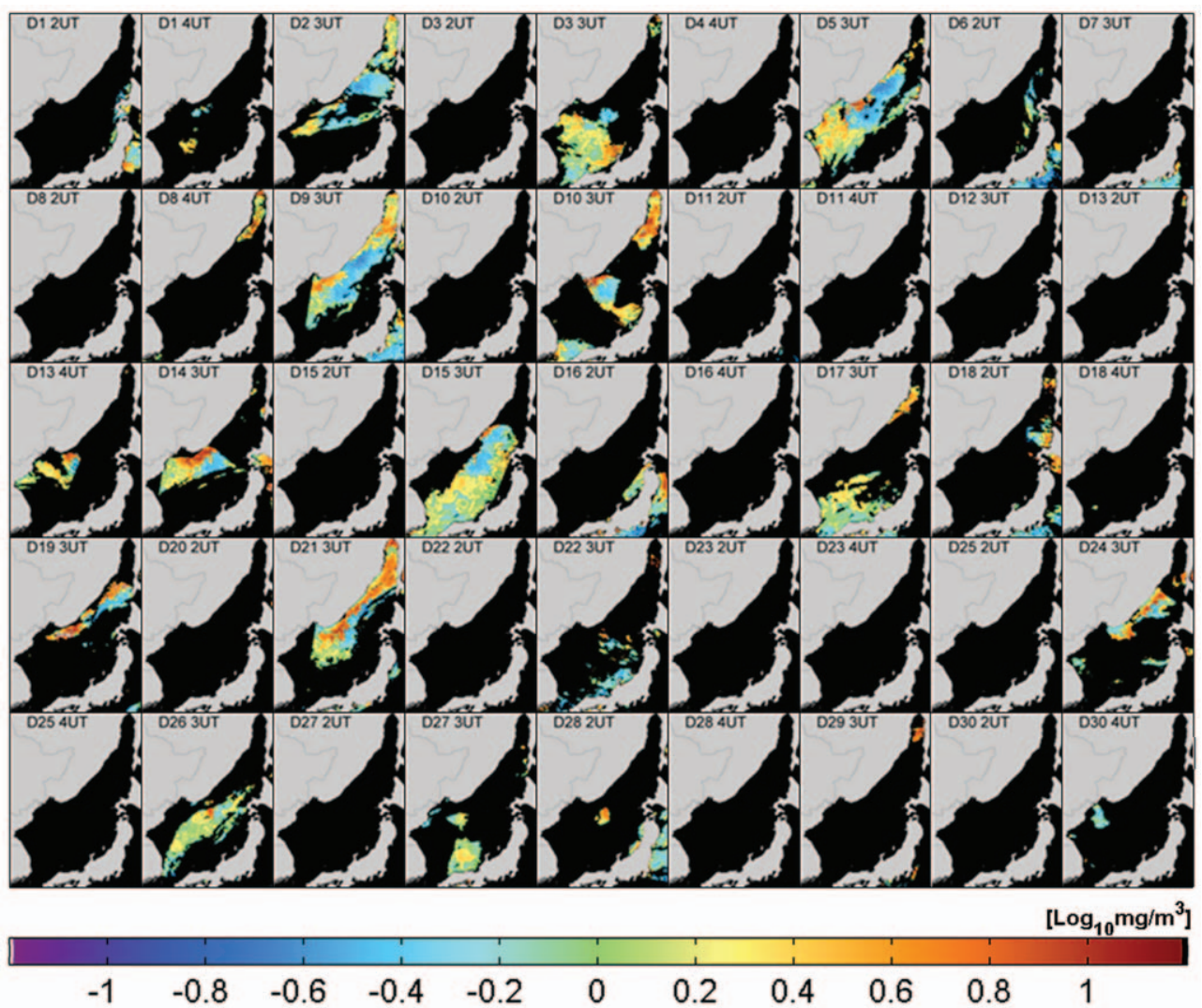

Fig. 2. Time series of level-2 SeaWiFS chlorophyll-a concentration images in April, 2003.

in the middle of the Japan Basin $\left(\sim 135^{\circ} \mathrm{E}, 42^{\circ} \mathrm{N}\right)$. By contrast, not many regions had any measurements during the month at many places. Locations included south of Vladivostok, east of East Korea Bay, west of the Tsugaru Strait and the Soya Strait, and west of Japan. The majority of the East Sea (75.68\%) showed an observational frequency of less than five as shown in Fig. 3(a). This is inferred to be related to specific cloud distributions.

We expect that the observation frequency can affect the accuracy and quality of composited monthly chlorophyll- $a$ concentration values. In addition, accuracy can depend on which methodology is used to determine the average for the generation of each time-composite map. Fig. 3(b) is an example of SeaWiFS level-3 monthly map for April, 2003 as provided by NASA/GSFC. High chlorophyll- $a$ concentrations $\left(>1 \log _{10} \mathrm{mg} / \mathrm{m}^{3}\right)$ were distributed along the Russian coast and the Tatarskiy Strait in the northern East Sea. Other regions with high values were detected at the northern leading edge of a mesoscale eddy at the eastern coast of Korea around $38^{\circ} \mathrm{N}$. Although there were 45 images for the month, many pixels in the composite map did not have any values due to the lack of satellite observations. By contrast, there was a pixel with many measurements of about 15 within a month, which can estimate average field with more stability than other neighboring pixels with quite a few measurements.

Chlorophyll- $a$ concentration values are liable to be estimated depending on the spatial and temporal capability of data sampling by different satellite 


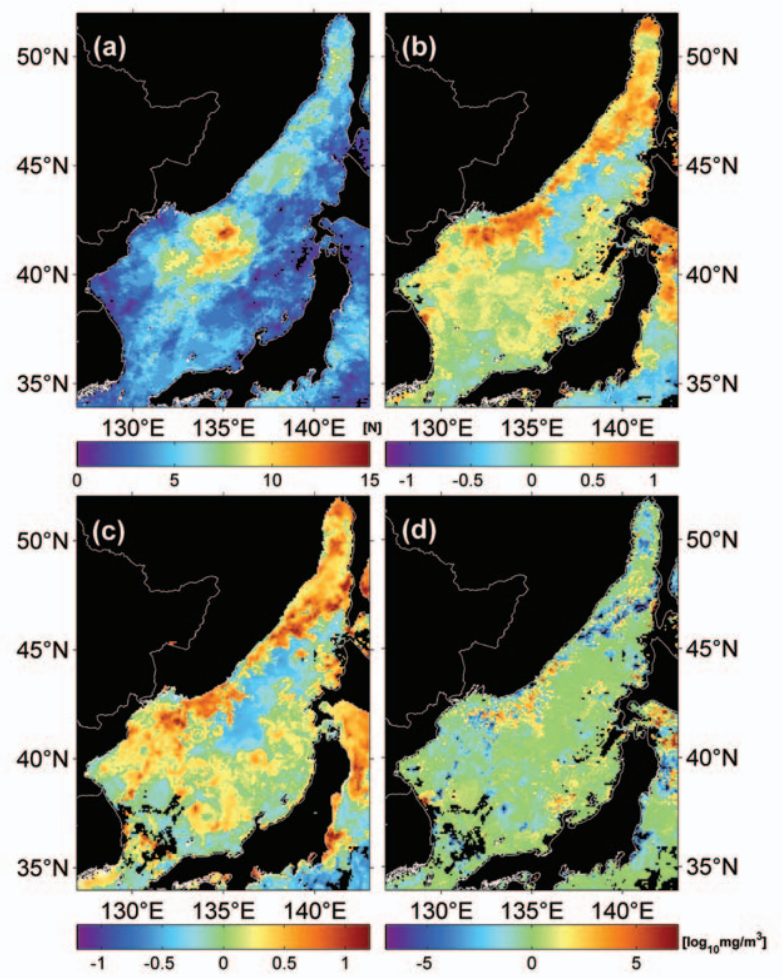

Fig. 3. (a) The number of pixels with good-quality chlorophyll-a concentration data from SeaWiFS for the month of April, 2003, a level-3 monthly map of NASA/GSFC (April 2003) from (b) SeaWiFS and (c) MODIS, and (d) difference between (b) and (c), (b) minus (c).

sensors. Fig. 3(d) illustrates differences between monthly maps from SeaWiFS and MODIS, SeaWiFS minus MODIS herein. On average, most of the differences for the log scale were close to zero (ratio 1) for the entire region. However, there were large differences at the frontal region where the spatial gradient of chlorophyll- $a$ concentrations was large, especially in the southeastern region off the Primorye coast. Chlorophyll- $a$ concentration values of SeaWiFS were much lower than MODIS by $5 \log _{10}$ $\mathrm{mg} / \mathrm{m}^{3}$ in the northern region of the East Sea, near the Tatarskiy Strait and west of Japan north of $45^{\circ} \mathrm{N}$. By contrast, the southeastern region from Vladivostok revealed positive differences, which means SeaWiFS values were occasionally higher than MODIS values.

Thus, an investigation of the differences between different satellite sensors and composite methods is further required. As previously mentioned, the management of differences in the observational frequencies of composited maps based on different methods is crucial. The characteristics of spatial and temporal distributions of chlorophyll- $a$ concentration data should be considered in the following averaging process.

\section{2) Removal of speckles}

Since speckles with extremely high chlorophyll- $a$ concentration values give rise to significant errors in the composite map, we removed problematic pixels based on the method developed by Park et al. (2012). After applying the speckle removal scheme, we estimated the average field by using simple average method to see the effect of the speckle. Fig. 4 shows the enlarged portion of a small area $\left(135-138^{\circ} \mathrm{E}, 42\right.$ - 
$45^{\circ} \mathrm{N}$ ) from the composite chlorophyll- $a$ concentration map before and after the removal process as an example. When the speckle-removal scheme was applied in this study, speckle-like high values disappeared. The majority of normal pixels have low values of less than $0.3 \log _{10} \mathrm{mg} / \mathrm{m}^{3}$, however, only one pixel, marked as a red circle in Fig. 4(a), showed a much higher value of about $18.70 \mathrm{mg} / \mathrm{m}^{3}$ than its

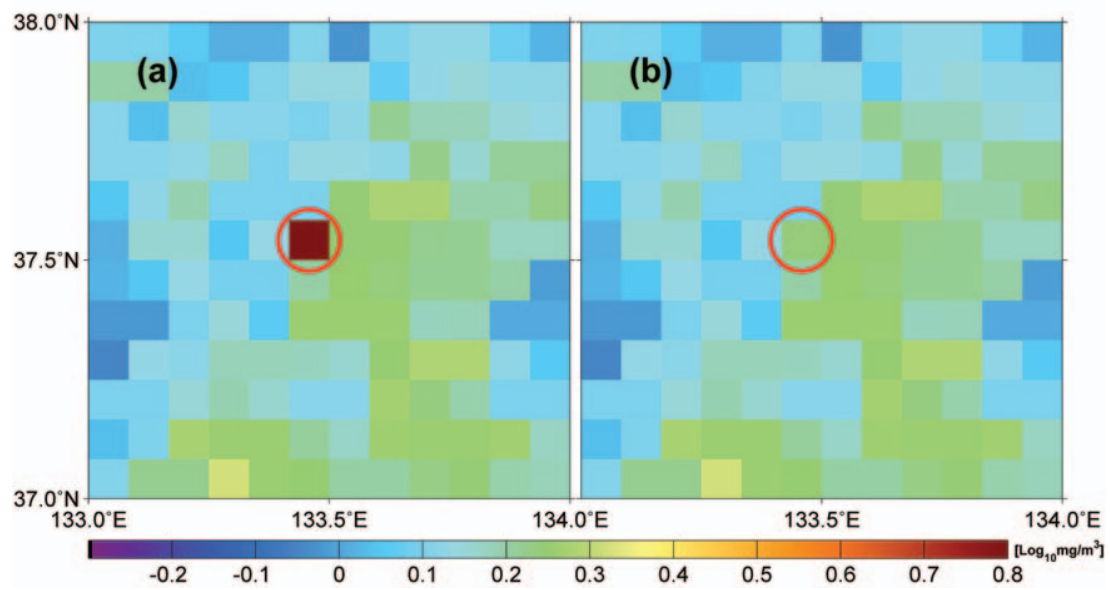

Fig. 4. Distribution of speckles with anomalously high chlorophyll-a concentration values, and simply-averaged maps of chlorophyll-a concentration values with (a) and (b) without speckles.

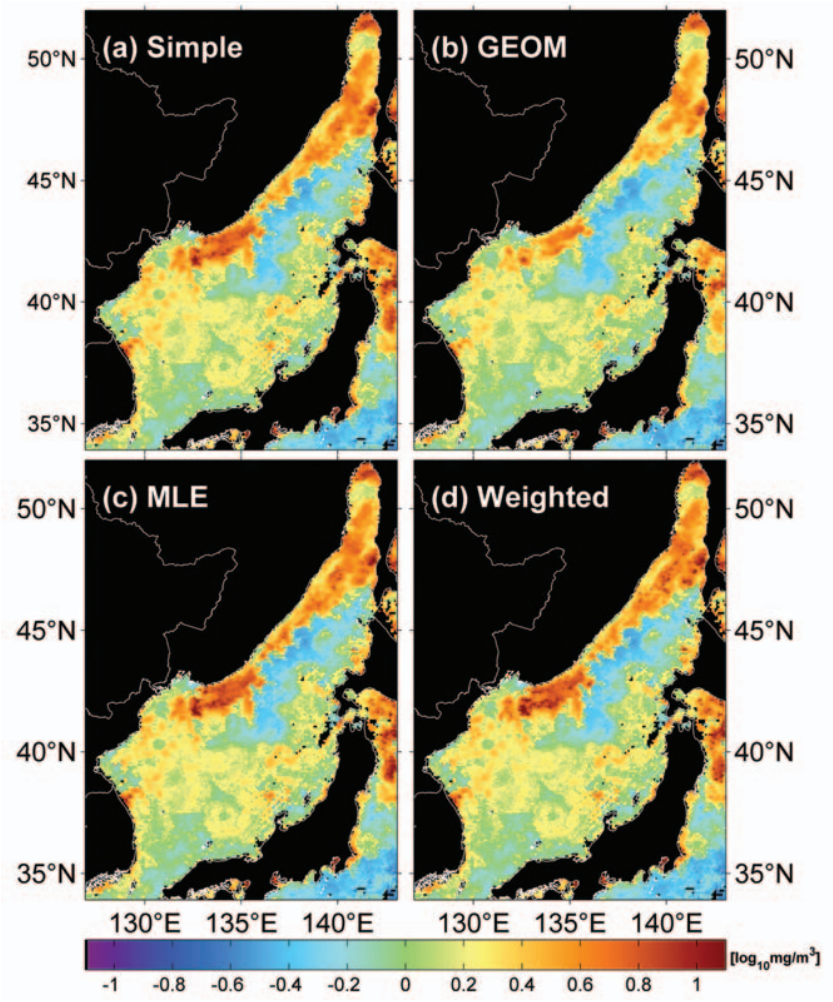

Fig. 5. Monthly map of chlorophyll-a concentration in April 2003 using (a) simple average method, (b) the MLE (Maximum Likelihood Estimation) method, (c) the GEOM (Geometric Mean), and (d) the weighted average method. 
neighboring pixel values. When we compared the two images in Fig. 4, neighboring non-speckle values seemed to be properly preserved even after the speckle removal process.

\section{3) Composite maps by different methods}

The composite maps in Fig. 5 were generated by the four methods as summarized in Table 1: the simple average $\left(\bar{X}_{\text {avg }}\right)$, the geometric mean $\left(\bar{X}_{\text {geom }}\right)$, the maximum likelihood estimation $\left(\bar{X}_{m l e}\right)$, and the weighted average $\left(\bar{X}_{\text {weighted }}\right)$. Overall, the distributions seemed not too different between the respective images by showing similar ranges from -0.8 to 1.2 $\log _{10} \mathrm{mg} / \mathrm{m}^{3}$. All the images exhibited a strong spring bloom with high chlorophyll- $a$ concentrations (>10 $\mathrm{mg} / \mathrm{m}^{3}$ ) in the regions along the Russian coast and south of Vladivostok. When the geometric mean was compared with the simple average, it tended to be underestimated. The highest value in Fig. 5(a) was greatly reduced to be similar to the value near the sub-polar front in the central region (Park et al., 2004). The Primorye region along the Russian coast illustrates dominant differences of about $1 \log _{10}$ $\mathrm{mg} / \mathrm{m}^{3}$ and $0.1 \log _{10} \mathrm{mg} / \mathrm{m}^{3}$ between Fig. 5(a) and 5(b), respectively. This tendency was similar to the comparison results with other methods of the maximum likelihood method or the weighted mean. Fig. 5(c) and 5(d) appear quite similar, but the weighted mean $\bar{X}_{\text {weighted }}$ in Fig. 5(d) seemed to be somewhat higher than $\bar{X}_{m l e}$. In order to investigate the effect of different methods of averaging, more detailed comparisons should be performed in the following sections.

\section{4) Difference between composited maps}

For more quantitative comparisons between the methods, we made six-pair scatter plots between the two methods out of the four methods in Fig. 6. Overall, the two methods showed good agreement regardless of the methods. However, detailed scrutinization revealed characteristic differences among the methods. Fig. 6(a) indicated the comparison between the simple average and the geometric mean. The highest frequency of chlorophyll- $a$ concentration greater than 800 was found at $0.2 \log _{10} \mathrm{mg} / \mathrm{m}^{3}$. Frequencies of about 100 were located between -0.5 to $0.8 \log _{10} \mathrm{mg} / \mathrm{m}^{3}$. The geometric mean was estimated much lower than the simple average, particularly at $0.5 \log _{10} \mathrm{mg} / \mathrm{m}^{3}$ of the simple average.

As mentioned previously, the geometric mean of chlorophyll- $a$ concentration values was underestimated all the time as compared with other methods (Fig. 6a,
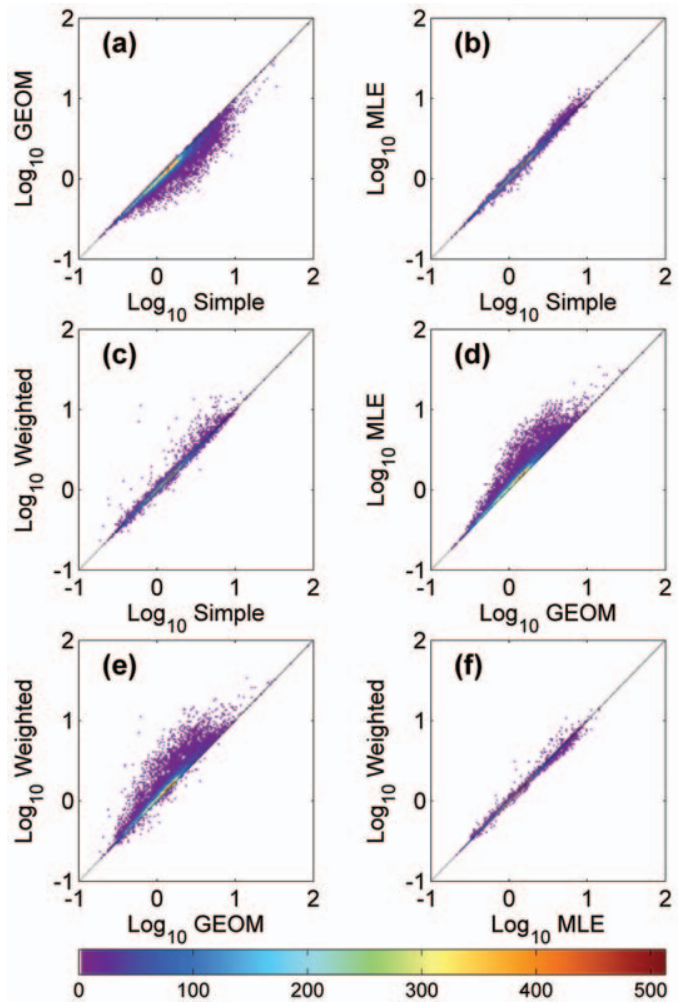

Fig. 6. Comparisons of chlorophyll-a concentration composite maps between the simple average and (a) the MLE, (b) the geometric mean, (c) the weighted average, respectively, and between (d) the MLE and the geometric mean, (e) the MLE and the weighted average, and ( $\mathrm{f}$ ) the geometric mean and the weighted average. 
Table 2. Statistical differences $\left(\log _{10} \mathrm{mg} / \mathrm{m}^{3}\right)$ between two average methods out of four representative composite methods

\begin{tabular}{c|c|c|c|c}
\hline \hline Differences & Mean Bias & RMSE & $r^{2}$ & $\mathrm{r}$ \\
\hline $\bar{X}_{\text {geom }}-\bar{X}_{\text {avg }}$ & -0.0641 & 0.07485 & 0.929 & 0.9639 \\
\hline $\bar{X}_{\text {mle }}-\bar{X}_{\text {avg }}$ & 0.0035 & 0.02764 & 0.9924 & 0.9962 \\
\hline $\bar{X}_{\text {weighted }}-\bar{X}_{\text {avg }}$ & 0.0079 & 0.04983 & 0.9753 & 0.9876 \\
\hline $\bar{X}_{\text {geom }}-\bar{X}_{\text {mle }}$ & -0.0676 & 0.08821 & 0.9222 & 0.9603 \\
\hline $\bar{X}_{\text {geom }}-\bar{X}_{\text {weighted }}$ & -0.0720 & 0.1017 & 0.897 & 0.9471 \\
\hline $\bar{X}_{\text {weighted }}-\bar{X}_{\text {mle }}$ & 0.0044 & 0.04803 & 0.977 & 0.9885 \\
\hline \hline
\end{tabular}

6d, and 6e). Similar trends were found in cases of the MLE and the weighted average in Fig. 6(d) and 6(e). The geometric mean was most scattered as compared with the weighted average (Fig. 6e). The MLE average showed good agreement with the simple average with less scatters of the points (Fig. 6b). The correlation coefficient between the two (MLE and simple average) was highest by 0.9962 (Table 2). This was similar to other cases such as the weighted average versus the simple average $(r=0.9876)$ and the weighted average versus the MLE ( $r=0.9885)$. Fig. 6(c) implies that the weighted average was overestimated at relatively high range of simple average by showing a mean bias of 0.0079 , which was also similar to the case of MLE. Detailed statistics of the differences, such as mean bias, rms error, $r^{2}$ value of the statistics, and correlation coefficient, are listed in Table 2.

Fig. 7 shows the histograms of differences between four composite maps for six cases of comparisons. The first plot (Fig. 7a) represents the comparison between simple average and geometric average. All the differences between the geometric mean and the simple average demonstrated a negative mean bias by -0.641 , which meant that the geometric average method was always liable to estimate chlorophyll- $a$ concentration values lower than the simple average method. The high frequencies of a positive range of ratios as presented in Fig. 7(d) and Fig. 7(e) support the tendency to underestimate the geometric mean as
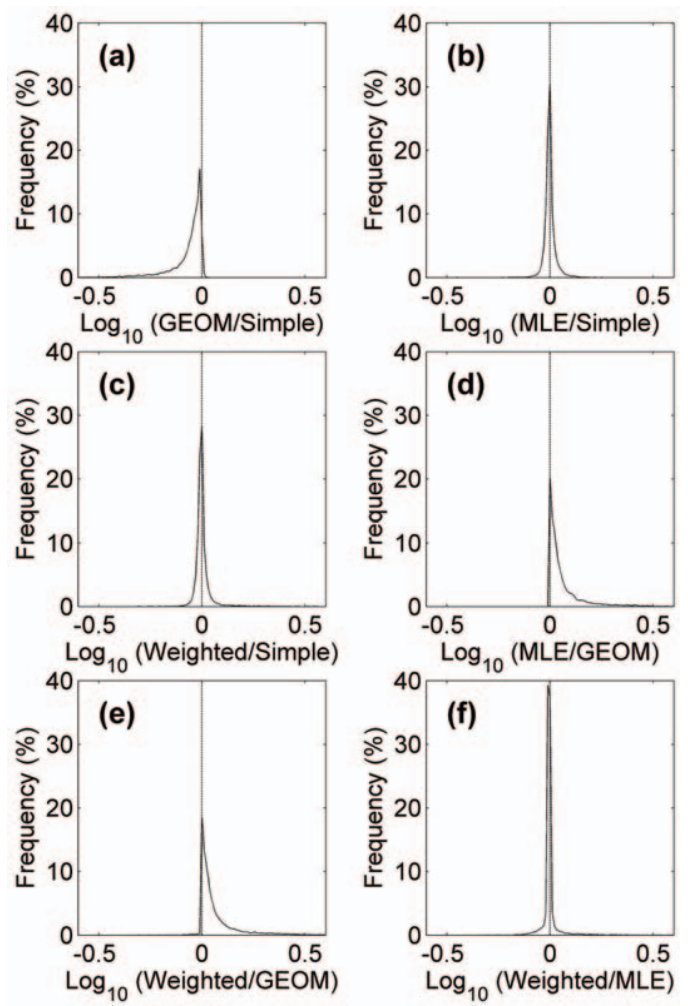

Fig. 7. Histograms of differences of chlorophyll-a concentration values in the composite maps: between the simple average and (a) the MLE, (b) the geometric mean, (c) the weighted average, respectively, and between (d) the MLE and the geometric mean, (e) the MLE and the weighted average, and ( $f$ ) the geometric mean and the weighted average.

compared with the MLE and the weighted mean as evident from negative biases of -0.676 and -0.720 , respectively. Our results coincide with previous results reported in the International Ocean Colouring Coordinating Group's Technical Report Number 4 (IOCCG, 2004) on the underestimation of the geometric mean method.

Except for the geometric mean, the simple averages were quite similar to the MLE and the weighted mean, as shown in Fig. 7(b) and 7(c) and as inferred from equally-skewed histograms toward negative or positive values of the ratios between the two methods. Fig. 7(f) demonstrated the smallest skewness by the highest counts around ratio 0 in the log scale. This implies that the weighted mean and 

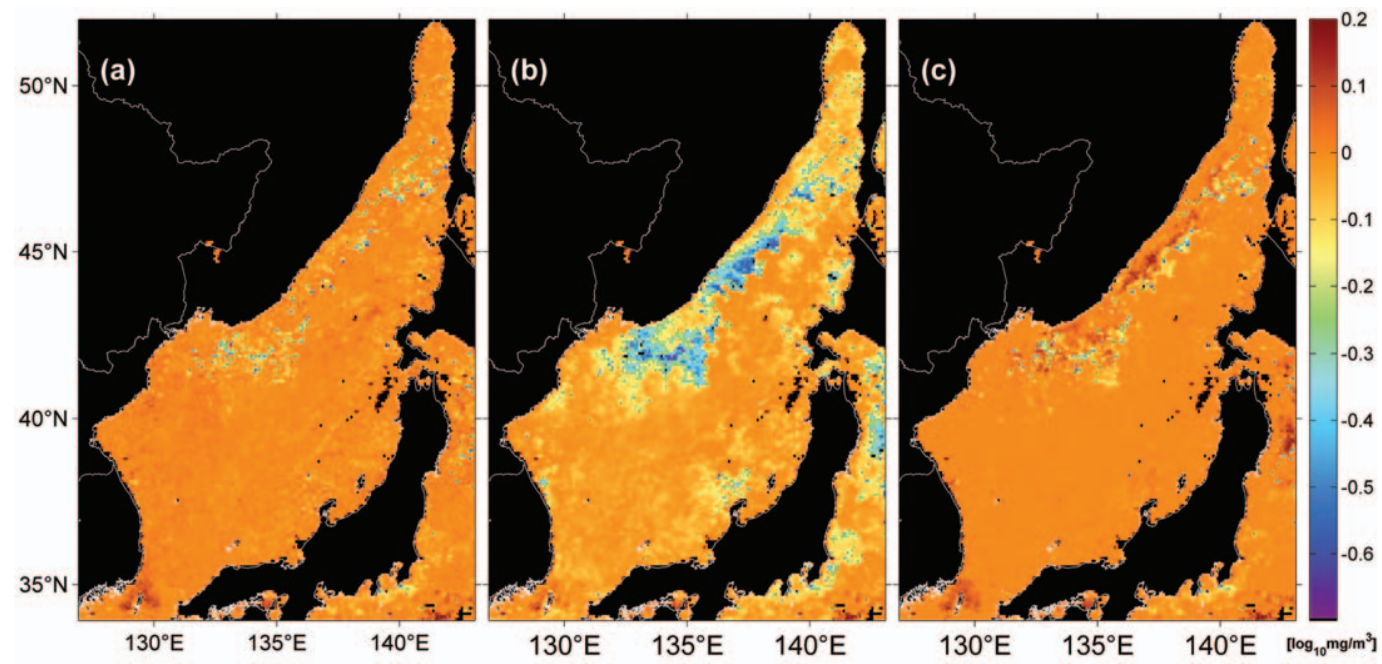

Fig. 8. Distribution of chlorophyll-a concentration ratios (log scale) from (a) the simple average, (b) the maximum likelihood method, and (c) the geometric mean to the weighted average.

the MLE were comparatively well coincident although there a fewer high scatters at high chlorophyll- $a$ concentration range greater than 0.5 at a log scale as shown in Fig. 6(f).

Fig. 8 shows the distribution of chlorophyll- $a$ concentration ratios (log scale) of the three methods with respect to the weighted mean. That is, Fig. 8(a) represents $\log _{10}\left(\bar{X}_{a v g} / \bar{X}_{\text {weighted }}\right.$ ) or $\log _{10} \bar{X}_{a v g}-\log _{10}$ $\bar{X}_{\text {weighted }}$ between the two averages, $\bar{X}_{\text {avg }}$ and $\bar{X}_{\text {weighted }}$. Since it was plotted in the logarithmic scale, the two averages will be the same if the ratio is zero. A positive (negative) value implies that the average is lower (higher) than the weighted average.

Most of the spatial grids in the entire study region showed a difference near 0 except for negative values near the Russian coast (Fig. 8a). This implies that chlorophyll- $a$ concentration composite values by the simple average method tended to be underestimated in the Russian coastal regions as compared with the weighted mean. By contrast, the geometric mean revealed highly negative values (Fig. 8b), which implies that the geometric means were underestimated more than the weighted average. The negative regions coincided with high chlorophyll- $a$ concentration values off the Russian coast. That is, the geometric mean method seemed to be poorly operated at the zones of high chlorophyll- $a$ concentration values.

The MLE average in Fig. 8(c) indicates characteristic differences at high chlorophyll- $a$ concentration regions with the weighted mean. The ratios were nearly zero in most of the East Sea, especially in the southern region of the sub-polar front extending zonally along $40^{\circ} \mathrm{N}$ roughly (Park et al., 2004). However, some of those showed high ratios of greater than 1 ( 0 herein in the logarithmic scale) and other regions adjacent to the high region exhibited negative values of about -0.2. From this distribution, it is inferred that the MLE tended to estimate chlorophyll- $a$ concentration mean higher or lower values as compared with the weighted average, particularly near the front of a chlorophyll- $a$ concentration a with large spatial gradient. Therefore, it is necessary to investigate the effect of data counts, participating in the averaging process within a given bin, on the resulting composite values depending on the selection of averaging methods.

\section{5) Effects of data uniformity on composite}



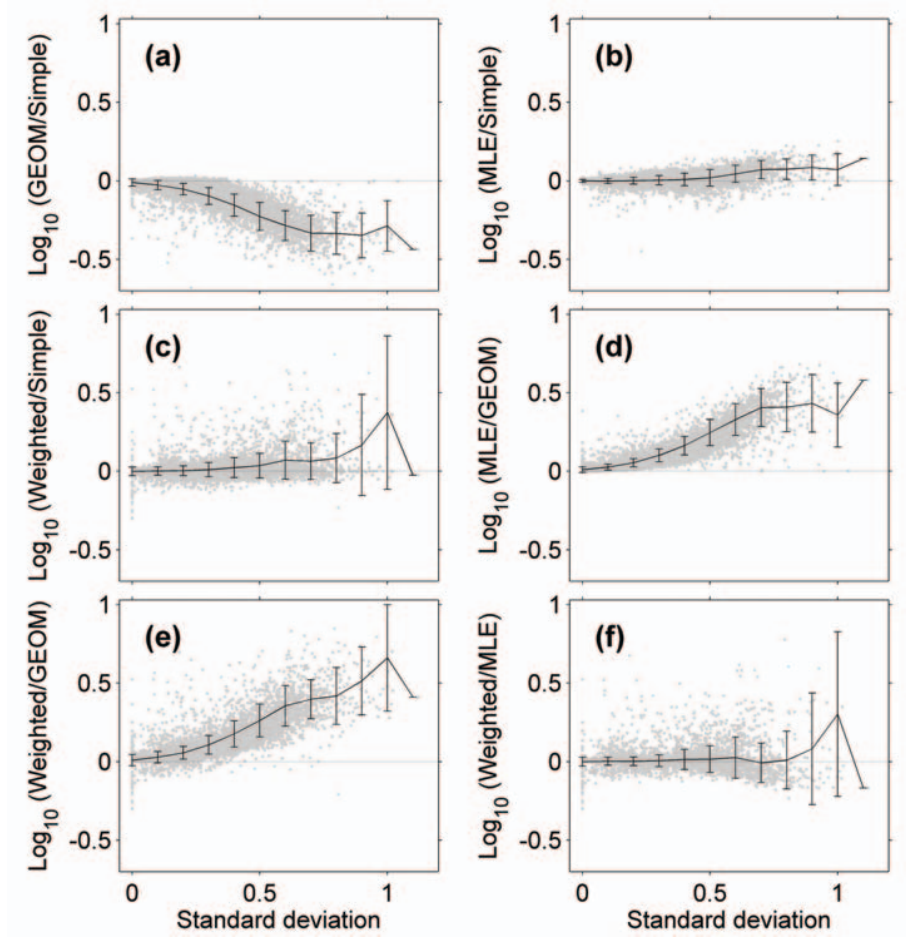

Fig. 9. Differences of chlorophyll-a concentration values in the composite maps as a function of standard deviation: between the simple average and (a) the MLE, (b) the geometric mean, (c) the weighted average, respectively, and between (d) the MLE and the geometric mean, (e) the MLE and the weighted average, and (f) the geometric mean and the weighted average.

\section{maps}

If there is small variance of the data set within a bin with a given spatial and temporal window, the resulting average will be estimated to be comparatively stable. However, in some cases when a gird point is located at the frontal region with a high spatial gradient or with a high temporal variability due to short-period bloom of phytoplankton, the average value is not likely to be used as a representative average. It depends on data sampling capabilities. To investigate this effect from the spatiotemporal uniformity, we estimated a standard deviation value within each bin for a monthly composite map.

Fig. 9 indicated the difference between the two selected composite methods as a function of standard deviation within a bin. As mentioned previously, it was obvious that the geometric mean was underestimated as compared with other methods such as the simple average method, the maximum likelihood method, and the weighted average as displayed in Fig. 9(a), 9(d), and 9(e) respectively. The trend to underestimate the geometric mean was amplified as the standard deviation increased for the other three methods. Since the MLE was developed by considering data variance within a bin, it tended to reduce the impact of large variances in chlorophyll- $a$ concentration data. Fig. 9(b) revealed that the MLE method was quite similar to the simple average regardless of data variance, although there was a weak increasing trend as the standard deviation increased. That is, the homogeneity of data within a bin decreased. In the case of the weighted average, its difference from the other three averages seemed to be low and within a small range of standard deviations 
Table 3. Averages estimated by the four methods (the simple average, the geometric mean, the maximum likelihood estimation, and the weighted average) before and after the removal process of speckles and improving the degree of the average, (before after)/before, in percentage at the positions of selected speckles at $A, B$, and $C$

\begin{tabular}{|c|c|c|c|c|c|}
\hline \multicolumn{2}{|c|}{ Method } & Simple Average & Geometric Mean & $\begin{array}{c}\text { Maximum } \\
\text { Likelihood Estimation }\end{array}$ & Weighted Average \\
\hline \multirow{3}{*}{$\begin{array}{c}\text { Speckle A } \\
\left(133.5^{\circ} \mathrm{E}, 37.5^{\circ} \mathrm{N}\right)\end{array}$} & Before & 6.4246 & 2.2279 & 5.2706 & 8.7557 \\
\hline & After & 1.7391 & 1.4330 & 1.6506 & 1.4371 \\
\hline & $\begin{array}{c}\text { Improved } \\
\text { percentage }(\%)\end{array}$ & 72.93 & 35.68 & 68.68 & 83.59 \\
\hline \multirow{3}{*}{$\begin{array}{c}\text { Speckle B } \\
\left(136.3^{\circ} \mathrm{E}, 42.9^{\circ} \mathrm{N}\right)\end{array}$} & Before & 5.6286 & 1.6500 & 6.3834 & 8.0286 \\
\hline & After & 2.0649 & 1.0863 & 2.1353 & 1.8485 \\
\hline & $\begin{array}{c}\text { Improved } \\
\text { percentage }(\%)\end{array}$ & 63.31 & 34.16 & 66.55 & 76.98 \\
\hline \multirow{3}{*}{$\begin{array}{c}\text { Speckle C } \\
\left(141.4^{\circ} \mathrm{E}, 50^{\circ} \mathrm{N}\right)\end{array}$} & Before & 7.9677 & 5.3285 & 8.5402 & 9.9956 \\
\hline & After & 5.2000 & 4.1110 & 4.9597 & 4.4935 \\
\hline & $\begin{array}{c}\text { Improved } \\
\text { percentage }(\%)\end{array}$ & 34.74 & 22.85 & 41.93 & 55.05 \\
\hline
\end{tabular}

of less than 0.5 as shown in Fig. 9(c) and 9(f). However, it appeared to be large as standard deviation reached high values. This tendency could be applicable to other comparisons with the geometric mean (Fig. 9e).

This result reflects comments publish by the IOCCG (2004) on the frontal region of the Gulf Stream. When they derived the ratios of the monthly mean chlorophyll- $a$ values based on the applied methods, the largest differences occurred in the dynamic frontal regions along the northern boundary of the Gulf Stream and in the vicinity of warm and cold eddies (IOCCG, 2004). In order to look for potential causes of the large differences in the frontal region, they inspected daily images used for a composite average map and found that a meander had begun to form and then pinched off southward to subsequently form a cold core ring. Since the East Sea is also one of the most dynamic marginal seas physically and biologically, the fronts of chlorophyll$a$ concentration values are well developed, as shown in Fig. 3(b) and 3(c). Thus, it is highly plausible that the activity of biological fronts with higher spatiotemporal variances will give rise to the differences in the resulting average field as shown in Fig. 9.

If a speckle is present in a bin for averaging, it will seriously affect the final average value. To avoid this, some criteria should screen the data for lower quality. We tested the effect of speckles on the averages by applying the four methods, which are listed in Table 3. At three arbitrarily selected positions of speckles in the East Sea, amounting to about $10 \mathrm{mg} / \mathrm{m}^{3}$, we applied the four methods to estimate average values. There were also large differences in the original averages between the four methods. However, it was greatly reduced from 1.4 to $5.2 \mathrm{mg} / \mathrm{m}^{3}$ depending on the methods after the application of the speckle removal scheme. Table 3 demonstrates that the effect of speckle removal was the most dominant in the weighted average. For example, for speckle A, the original weighted average of 8.75 was improved by about $83 \%$ after the speckle removal process. However, it was comparatively better than the MLE after the removal of speckles. The MLE method is known to be the most sensitive in the presence of speckles or in the frontal zone. Table 3 shows the impact of speckles on the MLE methods, which 

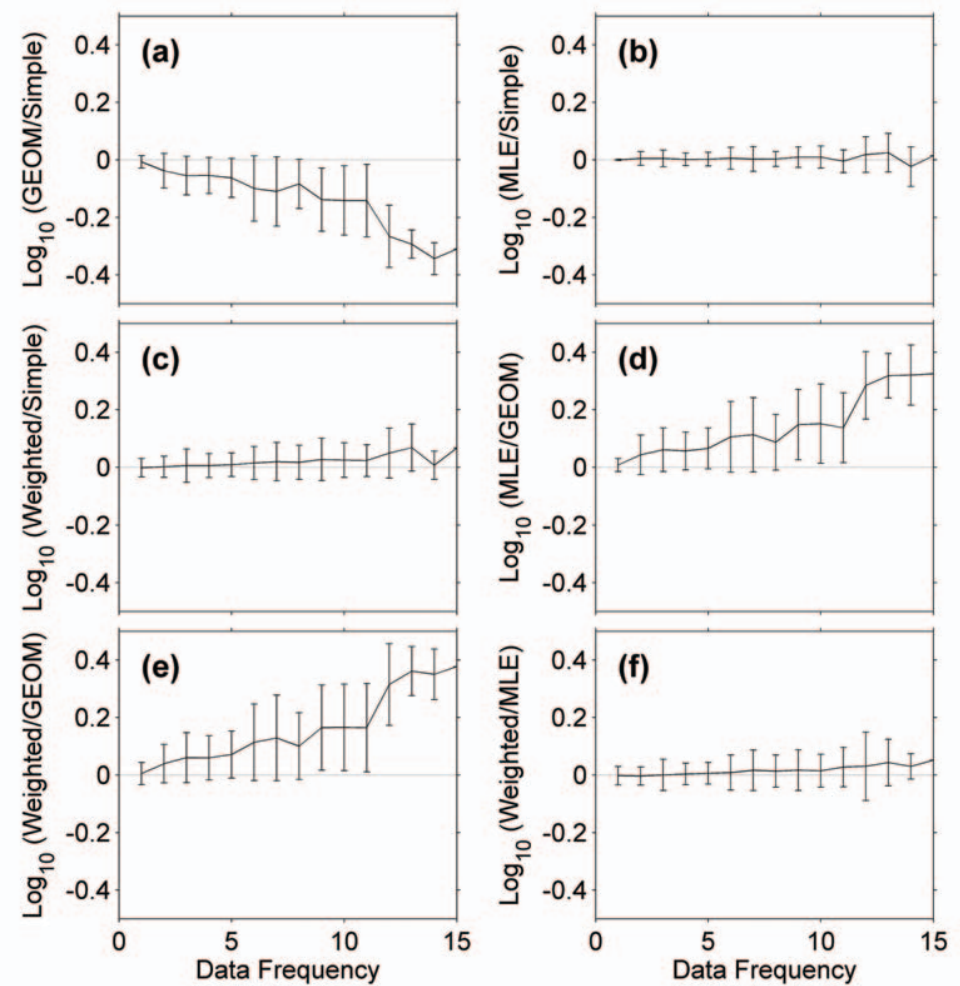

Fig. 10. Differences of chlorophyll-a concentration values in the composite maps as a function of data frequency: between the simple average and (a) the MLE, (b) the geometric mean, (c) the weighted average, respectively, and between (d) the MLE and the geometric mean, (e) the MLE and the weighted average, and (f) the geometric mean and the weighted average.

improved significantly from approximately $41 \%$ to $66 \%$.

\section{6) Effects of data sampling capabilities}

As shown in Fig. 2 and 3(a), each pixel of the monthly composite maps for April 2003 has a different number of satellite observations from zero to 15 . This sampling capability may affect the accuracy of the composited value. Because of the longer period and large cloud coverage, the discrepancy between the averaging methods will be increased as each chlorophyll- $a$ concentration value has more sparse temporal intervals. To examine the contribution of data sampling frequency for a month, we plotted the differences between the two average methods as a function of data frequency in Fig. 10.

While we expected that the differences would be reduced in proportion to data number frequency within a bin, it tended to increase as data number frequency increased. Even except for the geometric mean with large errors, all the other methods showed the same increasing trend. One possible explanation for this is that there were only a few pixels with a measurement frequency of greater than 10 within a month. This study did not support our hypothesis on data sampling capabilities because of fewer sampling numbers and the specific high cloud coverage of the East Sea.

\section{Summary and Conclusion}

Both SeaWiFS level-2 daily data and level-3 gridded chlorophyll- $a$ concentration data have been 
extensively used for diverse research. Since chlorophyll- $a$ concentration is a variable with a lognormal distribution, it should be carefully handled in the generation of time-averaged composite mapping. It should not be treated as a variable of sea surface temperatures (SST), which is one of the most representative oceanic variables with a nature of conservative property in the ocean. The chlorophyll- $a$ concentration value is not a conservative variable but a non-conservative and discontinuous variable depending on the oceanic biogeochemical environment including atmospheric conditions. Therefore, level-3 composite maps should consider the log-normal distribution in order to take the rapidly-varying variability of chlorophyll- $a$ concentration values into account and their remarkable horizontal and vertical variations. The GSFC scientific community has made great endeavors to integrate properties in the generation of composited maps by suggesting diverse methods.

In this study, we produced level-3 monthly composite images from daily level-2 SeaWiFS chlorophyll- $a$ concentration data in the East Sea by applying four averaging methods (the simple average, the geometric mean, the maximum likelihood average, and the weighted mean) that the scientific community has suggested to date. SeaWiFS chlorophyll- $a$ concentration images have been reported to have extremely high speckle values due to the partial failure of atmospheric correction, cloud problems, and many other sources (Park et al., 2012). Even after standard data reprocessing was performed several times, the speckles still remained (Patt et al., 2003). Thus, we classified chlorophyll speckles with anomalously high chlorophyll- $a$ concentrations from normal pixels and eliminated these from the subsequent composite procedure prior to performing each average method.

Comparing the simple average and the geometric mean revealed that the geometric mean method tended to underestimate the chlorophyll- $a$ concentration in every case. This trend was also found comparing other methods such as the maximum likelihood method or the weighted mean. The weighted averaging method was quite analogous to the simple averaging method; however, it tended to overestimate chlorophyll- $a$ concentration at its high range. The maximum likelihood method was nearly identical to the simple average method by demonstrating small variations between the two. However, it also had the disadvantage that it was very sensitive to the existence of speckles within a bin for the composite procedure. When the standard deviation of the chlorophyll- $a$ concentration within a bin was relatively large, the geometric mean and the weighted mean were predominantly deviated from other averages at all ranges of chlorophyll- $a$ concentration values. However, the weighted average method was greatly improved by the removal process of speckles. Other methods also provided dissimilar mean values with large distinctions at ranges with high standard deviations and with significant scatters in term of time and space.

NASA is currently using the simple average method after investigating the advantages and disadvantages of composite methods through several research projects. To determine the high spatial and temporal variability of chlorophyll- $a$ concentration and its log-normal distribution statistically, it is necessary to consider the inherent biological properties of chlorophyll- $a$ in the generation of composite maps. The MLE method is a useful method for considering the log-normal distribution. However, it is not used by NASA because it is known to be very sensitive in the frontal zone with high spatial variations. Moreover, it responds sensitively to the existence of speckles. The geometric averaging method poorly estimates chlorophyll- $a$ mean values 
as a result of significantly underestimating to what extent the high chlorophyll- $a$ concentration values increased.

In light of this, for the time being, it might be more appropriate to use the simple averaging method or the weighted averaging method in the composite process using chlorophyll- $a$ concentration data in the East Sea rather than other methods. However, the speckles should be eliminated prior to using the weighted mean method. Based on additional information about biological processes and intensive in-situ measurements being collocated with satellite data, more robust methodology optimized to the East Sea should be investigated by incorporating the chlorophyll- $a$ concentration variability into the level3 composite map.

\section{Acknowledgement}

This research was a part of the project entitled "Research for applications of Geostationary Ocean Color Imager (GOCI)" funded by the Ministry, Land, Transport and Maritime Affairs (MLTM), Korea. This study was partly supported from the project entitled "Long-term change of structure and function in marine ecosystems of Korea" of MLTM.

\section{References}

Ahn, Y.H., 2000. Development of remote sensing reflectance and water living radiance models for ocean color remote sensing technique, Korean Journal of Remote Sensing, 16(3): 243-260.

Ahn, Y.H. and J.E. Moon, 1998. Specific absorption coefficients for the chlorophyll and suspended sediments for the chlorophyll and suspended sediment in the Yellow and Mediterranean Sea, Korean Journal of Remote Sensing, 14(4): 353-365.

Aitchison, J. and J.A.C. Brown, 1957. The lognormal distribution, Cambridge University Press, 176 p.

Baker, M.A. and C.H. Gibson, 1987. Sampling turbulence in the stratified ocean: statistical consequences of strong intermittency, Journal of Physical Oceanography, 17: 1817-1836.

Campbell, J.W., J.M. Blaisdell, and M. Darzi, 1995. Level-3 SeaWiFS data products: spatial and temporal binning algorithms, NASA Technical Memorandum, 32:1-73.

Chae, H.J. and K.-A. Park, 2009. Characteristics of speckle errors of seaWiFS chlorophyll- $a$ concentration in the East Sea, Journal of Korean Earth Science Society, 30: 234-246.

Crow, E.L. and K. Shimizu, (Eds.), 1988. Lognormal Distributions: Theory and Applications, New York: Marcel Dekker Inc., 387 p.

Gordon, H.R. and A. Morel, 1983. Remote Assessment of Ocean Color for Interpretation of Satellite Visible Imagery: A Review. In: Lecture Notes on Coastal and Estuarine Studies, edited by R.T. Barker, N.K. Mooers, M.J. Bowman, and B. Zeitzschel, Springer-Verlag, New York.

Hooker, S.B., W.E. Esaias, G.C. Feldman, W.W. Gregg, and C.R. McClain, 1992. An overview of SeaWiFS and ocean color, NASA Technical Memorandum, 1: 1-25.

Hu, C., K.L. Carder, and F.E. Muller-Karger, 2000. Atmospheric correction of SeaWiFS imagery: assessment of the use of alternative bands, Applied Optics, 39: 3573-3581.

Hu, C., K.L. Carder, and F.E. Muller-Karger, 2001. How precise are SeaWiFS ocean color estimates? Implications of digitization-noise errors, Remote Sensing of Environment, 76: 
239-249.

IOCCG, 2004. Guide to the creation and use of ocean-colour, level-3, binned data products, D. Antoine (Ed.), Reports of the international Ocean-Colour Coordinating Group, 4: 1-88.

Jeong, J.C. and S.J. Yoo, 2002. Comparison of CZCS and SeaWiFS pigments for merging the higher level ocean color data, Korean Journal of Remote Sensing, 18(5): 299-303.

Kim, E., Y.J. Ro, and D. Jeon, 2010. Application of SeaWiFS chlorophyll- $a$ ocean color image for estimating sea surface currents from Geostationary Ocean Color Imagery (GOCI) data, Korean Journal of Remote Sensing, 26(2): 209-220.

McClain, C.R., K. Arrigo, W.E. Esaias, M. Darzi, F.S. Patt, R.H. Evans, J.W. Brown, C.W. Brown, R.A. Barnes, and L. Kumar, 1995. SeaWiFS algorithms, part 1, NASA Technical Memorandum, 28: 1-38.

Moon, J.E., Y.H. Ahn, J.H. Ryu, and P. Shanmugam, 2010. Development of ocean environmental algorithms for Geostationary Ocean Color Imager (GOCI), Korean Journal of Remote Sensing, 26(2): 189-207.

Morel, A. and L. Prieur, 1977. Analysis of variations in ocean color, Limnology and Oceanography, 22(4): 709-722.

O’Reilly, J.E., S. Maritorena, B.G. Mitchell, D.A. Siegel, K.L. Carder, S.A. Garver, M. Kahru, and C. McClain, 1998. Ocean color chlorophyll algorithms for SeaWiFS, Journal of Geophysical Research, 103: 24937-24953.

Park, K.-A., H.-J. Chae, and J.-E. Park, 2012.
Characteristics of satellite chlorophyll-a concentration speckles and a removal method in composite process in the East/Japan Sea, International Journal of Remote Sensing, in press.

Park, K.-A., J.Y. Chung, and K. Kim, 2004. Sea surface temperature fronts in the East (Japan) Sea and temporal variations, Geophysical Research Letter, 31, L07304, doi:10.1029/ 2004GL019424.

Patt, F.S., R.A. Barnes, R.E. Eplee Jr., B.A. Franz, W.D. Robinson, G.C. Feldman, S.W. Bailey, J. Gales, P.J. Werdell, M. Wang, R. Frouin, R.P. Stumpf, R.A. Arnone, R.W. Gould, P.M. Martinolich, V. Ransibrahmanakul, J.E. O'Reilly, and J.A. Yoder, 2003. Algorithm updates for the fourth SeaWiFS data reprocessing, NASA Technical Memorandum, 22: 1-74.

Ryu, J.H., J.E. Moon, J.E. Min, and Y.H. Ahn, 2007. Monitoring the coastal waters of the Yellow Sea using ferry box and SeaWiFS Data, Korean Journal of Remote Sensing, 23(4): 323-334.

Suh, Y.S., N.K. Lee, L.H. Jang, J.D. Hwang, S.J. Yoo, and H.S. Lim, 2002. Characteristic response of the OSMI bands to estimate chlorophyll-a, Korean Journal of Remote Sensing, 18(4): 187-199.

Yoon, H.-J., H.-K. Byun, and K.-S. Park, 2005. Temporal and spatial variations of SST and ocean fronts in the Korean Seas by empirical orthogonal function analysis, Korean Journal of Remote Sensing, 21: 213-219. 